\title{
Medical Informatics in Morocco: Casablanca Medical Informatics Laboratory
}

\author{
M. Bennani Othmani', S. Diouny' ${ }^{2}$ K. Balar ${ }^{1}$ \\ 'Hassan II University, Medical Faculty of Casablanca: Casablanca Medical Informatics Laboratory \\ ${ }^{2}$ Chouaib Doukkali University, Faculty of Letters and Humanities, English Studies Program, El Jadida
}

\begin{abstract}
Summary
Background: In 2005, Medical Informatics Laboratory (CMIL) became an independent research unit within the Faculty of Medicine and Pharmacy of Casablanca. CMIL is currently run by three persons (a university professor, a data processing specialist and a pedagogical assistant). The objectives of CMIL are to promote research and develop quality in the field of biomedical data processing and health, and integrate new technologies into medical education and biostatistics. It has four units: Telehealth Unit, Network Unit, Biostatistics Unit, Medical data processing Unit. Objectives: The present article seeks to give a comprehensive account of Casablanca Medical informatics laboratory (CMIL) activities. For ease of exposition, the article consists of four sections: Section I discusses the background of CMIL; section II is devoted to educational activities; section III addresses professional activities; and section IV lists projects that CMIL is involved in.

Results: Since its creation, CMIL has been involved in a number of national and international projects, which have a bearing on Telemedicine applications, E-learning skills and data management in medical studies in Morocco.

Conclusions: It is our belief that the skills and knowledge gained in the past few years would certainly enrich our research activities, and improve the situation of research in Medical informatics in Morocco.
\end{abstract}

\section{Keywords}

Medical informatics, Morocco, telemedicine, distance education, hospital information systems

Geissbuhler A, Haux R, Kulikowski C, editors. IMIA Yearbook of Medical Informatics 2007. Methods Inf Med 2007; 46Suppl 1: $138-40$

\section{Introduction}

In recent years, Medical informatics has captured the interest of professionals from different disciplines, whether they are clinicians or computer specialists. North American and Europe have seen real advances in the understanding of different types of Medical informatics applications. However, if these advances have helped to take care of the special needs of the Medical communities to which they belong, they have not, on the other hand, begun to make an impact in developing countries. For example, in Morocco, little progress has been registered in the field of Medical informatics whether in the area of academic studies, or research. It is with the hope to promote this area of research that Medical Informatics as a new field of interest was created in Morocco in 1997. It is in this spirit that the present article seeks to give a comprehensive account of Casablanca Medical informatics laboratory (CMIL) activities. For ease of exposition, the article consists of four sections: Section I discusses the background of CMIL; section II is devoted to educational activities; section III addresses professional activities; and section IV lists projects that CMIL is involved in.

\section{Background}

Before discussing the objectives of the laboratory, it is important to note that
CMIL was initially part of the Biostatistics and Epidemiology Laboratory at the Medical school of Casablanca. Six years later, Medical Informatics Laboratory (CMIL) became autonomous following a decision by the Scientific Committee of the Medical School. CMIL consists of four units, run by a team of three persons (a university professor, a data processing specialist and a pedagogical assistant): Telehealth Unit, Network Unit, Biostatistics Unit, Medical data processing Unit. The objectives of CMIL are (1) to promote research and develop quality in the field of biomedical data processing and health, (2) to improve research methodology in medical informatics application, and (3) to integrate new technologies into medical education and biostatistics.

\section{Educational and Training Activities}

CMIL ensures the teaching of biostatistics for the first cycle of the Medical studies at the Faculty of Medicine in Casablanca and Marrakech. In addition, it trains residents. It is important to note that medical informatics is a medical major; the DSM (Diploma in medical specialty) degree is gained in 4 years. Within the framework of continuous education, CMIL in responsible for a number of modules in different university degrees, such as Infection Control degree, Oral Implantology degree, Di- 
ploma in Neurosciences, and Master of Biology Sciences. In addition to these activities, CMIL organizes several seminars, round-table discussions for Ibn Rochd Hospital university professors, residents and interns. Key research areas include epidemiological data analysis, medical data codification, bibliographical research and multimedia production, etc.

\section{Professional Activities}

\section{Telemedicine}

Our platform is equipped with a speedy internet connection, 4 ISDN Lines (Marnis), and a Satellite connection, installed in 2004. People with a special interest in Telemedicine takes advantage of the different equipments that the Telemedicine Unit has: a microscope with camera for telepathology, a digitalizer for radiological films, computed tomography (CT) and magnetic resonance imaging. CMIL has also developed internal technical devices to optimize/upgrade all the available resources of an amphitheatre of a bigger capacity.

\section{CMIL'S Telemedicine activities}

Since its creation, university teachers, residents and interns have benefited from services and resources that Telemedicine unit offers. So far, CMIL has taken part in four main activities: First, clinical case discussions which involve medical staff in different specialities (radiology, gastroenterology, gynaecology). The purpose of this session is to present a medical case and participants provide feedback on diagnosis and prescription. Second, teleeducation allows participants to follow online medical courses (e.g., coelio- scopy). Third, visioconferences, the purpose of which is to exchange and share experiences and discuss future orientations with our partners. Finally, online surgery sessions in which our surgery residents (e.g., ophthalmology, otolaryngology, and general surgery) follow a surgical operating act from one of our foreign partner.

\section{E-learning}

In collaboration with Hassan II University, we set up an E-learning Open source platform, through which, CMIL offers students in Neurosciences and faculty the possibility of studying medical data processing. This first initiative represents a good example to follow. CMIL also contributed to the implementation of an E-learning University Resources Centre, the objectives of which are (1) to train teachers and academics in Information technology communication; (2) to train faculty and academics in online courses production, and (3) to disseminate knowledge and exchange experience.

\section{Health information system (HIS)}

CMIL participated in the elaboration of the Master plan of Ibn Rochd Hospital. It assures the direction of the HIS project. The purpose of this project is to come up with a solution, which should assure a coupling in real time of the flow of information in support of medical education and patient care (administrative, medical and nursing), of the physical flow (flow of medical materials, medicines, blood samples) and activities relative to the patients (care, prescriptions, exams, medical or surgery acts).

The main expectations of the future $\mathrm{SIH}$ can be grouped in three main categories: 1. Data recording relative to the vari- ous steps of medical care: Diagnosis, prescriptions, and results.

2. Information dissemination: exchange of information disseminators, e.g., medicine prescription must be exchanged into an order with the pharmacy.

3. Administrative and medical decisions: control panel allows analyzing medical activity, costs by patient, and stay by patient, etc.

\section{Projects}

The main achievements of CMIL are Multimedia Productions in Telemedicine, archives in Gynaecology (AMIG) and general Surgery (AMIC), a Streaming server of Multimedia productions of the Faculty of Medicine of Casablanca. The main projects that CMIL is involved in are listed below:

International NetAdded Project (New Technologies to Avoid Digital Division in e-divided areas) whose purpose is to create research centres to disseminate research results for the implementation of the European Community sixth framework programme.

International EMISPHER Project (Euro-Mediterranean Internet-Satellite Platform for Health, Education and Research) co-funded by the European Commission in the frame of the programme EUMEDIS; it aims at promoting cooperation between the countries of the Mediterranean area.

International ARMED Project (Antimicrobial Resistance in MEDiterranean region) is an international research project investigating antimicrobial resistance in a number of Mediterranean countries through the collection of comparable and validated antimicrobial resistance data as well as information about antibiotic consumption patterns and infection control initiatives.

National early periodontitis project aims to study the prevalence of early peri- 
odontitis in young people aged 10 to 18 in different areas of the kingdom. Casablanca Cancer Registry Project, the first of its kind in Morocco, seeks to identify and record exhaustively all cancer cases in the Casablanca area.

University National E-learning Project attempts to train Moroccan University teachers in the use of E-learning with a view to persuading them to produce their own online courses.

\section{Conclusion}

Introduction of medical informatics in the health care and medical education system is of prime importance. Still, this area of work has not been given due attention among the health care profession in Morocco; little progress has been registered in the field of medical informatics whether in the area of academic studies, or research in Morocco. However, it is crucial to note that despite its relatively short history and its limited human resources, CMIL has succeeded in breaking new grounds to meet the exigencies and take care of the special needs of the medical data processing community. CMIL is currently embarking on a number of national and international projects. We believe that our perspectives and ambitions depend on the collaboration of various specialized centers with a long tradition in medical informatics. Such cooperation would certainly contribute to the mission of CMIL, in particular, continuous training for our team. It is our belief that the skills and knowledge we have gained over the past few years would certainly enrich the above research activities, and improve the situation of research in Medical informatics in Morocco. The following recommendations should be taken seriously by health professionals:

1. Development of plans for the introduction of medical informatics in the whole health system so as to cover the needs of users.

2. Allocation of financial and human resources to support health informatics plans.

3. Promotion of public awareness to sensitize health care professionals on the importance of medical informatics and their specific role in its use.

\section{References}

1. Yu H, Hripcsak G. A Large Scale, Cross-Disease Family Health History. In: Proceedings of American Medical Informatics Association (AMIA) Symposium 2001. p. 1162.

2. Hersh WR. Medical Informatics: improving health care through information. J Am Med Assoc 2002; 288: 1955-8.

3 Shortliffe EH, Wiederhold G, Perreault LE, Fagan LM. Medical Informatics : Computer Applications in Health Care and Biomedicine. 2nd ed. New York: Springer Verlag; 2000.

4. Bennani Othmani M. Expérience de la Faculté de Médecine de Casablanca en Télémédecine Journal du praticien XIV, 2, juin 2006: 53.

5. M. Berg Implementing information systems in health care organizations: myths and challenges. Int J Med Inform 2001; 64: 143-56.

\author{
Correspondence to: \\ M. Bennani Othmani \\ Faculté de Médecine de Casablanca \\ 19 rue Tarik Ibn Ziad \\ Laboratoire d'Informatique Médicale \\ Casablanca, Maroc \\ Tel/ Fax : +21222299338 \\ E-mail: m.bennani@fmpc.ac.ma
}

